\title{
Research on the Profit Distribution of Logistics Company Strategic Alliance Based on Shapley Value

\author{
Huang Youfang ${ }^{1,}$, Ye Weilong ${ }^{1, b}$ and Zhou Feifei $i^{1, c}$ \\ ${ }^{1}$ Shanghai Maritime University, China
} \\ ayhuang@shmtu.edu.cn, bsqhuang@163.com, caprilzeit@126.com
}

Key Words: Shapley value; Strategic alliance; Logistic company; Internationalization

\begin{abstract}
Strategic alliance is an important business mode for Chinese logistics companies' internationalization, and the profit distribution among companies is the key issue maintaining the alliance's stability. This article tries to solve the profit distribution issues in the international strategic alliance based on Shapley value, meanwhile, points out the problems still remain in the original model, establishes a new model by revising Shapley value method based on considering elements including risks, investments, extra contribution and company capability. The new model has been tested and verified, and can ensure more reasonable profit distribution among alliance members, and can benefit the persistency of the alliance.
\end{abstract}

\section{Introduction}

The total value of logistics in Chinese society reached the number of 125.4 trillion Yuan in 2010, increased by $15 \%$. The coefficient of logistics demand is $1: 3.13$, which means every GDP output needs 3.13 units of support from logistics. Meanwhile, the foreign direct investment of China has increased 1.2 times since 5 years ago. With the development of both the logistics industry and the foreign trade, logistics service must support the growth with lower cost and higher efficiency, local companies' going global is more than necessary. However, it's hard for a single company to realize the internationalization due to the complicated operations and limited resources. Companies can unite the enterprises that have advantages in different parts of the international supply chain through strategic alliance. The final purpose of a strategic alliance is to optimize each member's own benefits. The method of profit distribution affects the stability and the profits of the alliance directly. Thus, there are numbers of researches on the methods of distributing profit. During 1950s, Nash and Shapley researched on the problem using game theory. The method of Shapley value was put forward by Shapley L.S., and is a mathematic way aiming to solve the distribution problems among multiple members. Chen Zhi and Duan Guijun(2005) revised Shapley model by introducing a comprehensive factor G; Zhang Yawen(2009) revised Shapley model by taking into account the possible relationship within the alliance; Li Ouyang(2011) established a horizontal profit distribution model for strategic alliance for 3rd-party logistics companies. This paper focuses on the research and presentation of Shapley Value method, and revises the model by combining the facts of Chinese logistics companies’ internationalization.

\section{Shapley Value Method[1]}

When there are multiple companies in pursuit of profits while their activities are not against each other, the increase of cooperation among members won't decrease benefits. The cooperation among the total $\mathrm{N}$ enterprises will bring the maximum benefit $\mathrm{V}(\mathrm{N})$. Assume a set $N=\{1,2 \ldots . n\}$, if any subset $\mathrm{S}(S \in N)$ corresponds to an eigenfunction $\mathrm{V}(\mathrm{S})$, there into Eq. 1.

$$
\begin{aligned}
& V(\varnothing)=0, \\
& V\left(S_{1} \cup S_{2}\right) \geq V\left(S_{1}\right)+V\left(S_{2}\right), S_{1} \cap S_{2}=\varnothing,\left(S_{1} \subseteq N, S_{2} \subseteq N\right) .
\end{aligned}
$$

$\mathrm{V}(\mathrm{S})$ practically means the profit created by strategic alliance $\mathrm{S}$, and is the maximum total revenue among the members of $\mathrm{S} .[\mathrm{N}, \mathrm{V}]$ is called the cooperative game among n people. $\mathrm{X}_{\mathrm{i}}$ means 
company i's maximum gross income in the cooperation which reaches the maximum benefit $\mathrm{V}(\mathrm{N})$. In the cooperation $\mathrm{N}$ the cooperative game distribution strategy can be shown as $x=\left(x_{1}, x_{2} \ldots . x_{n}\right)$. The alliance can only be successful with the conditions that $\sum_{i=1}^{n} x_{i}=V(N)$, and $x_{i} \geq V(i), i=1,2 \ldots . . n$. The benefit got by each member under strategic alliance $\mathrm{N}$ is called Shapley Value, based on Shapley method, written as $\varnothing_{i}(V),(i=1,2, \ldots . n)$, the solution is Eq. 2 and Eq. 3. $|s|$ stands for the numbers of elements in the subset $S$; $n$ stands for the numbers of elements in set $N$. V(s) is the benefits under the combination of subset $S ; w(s)$ is a weighted term; $v(s \backslash i)$ stands for the benefits of $\mathrm{S}$ after removing the benefit of company $\mathrm{i}$.

$$
\begin{aligned}
& \varnothing_{i}(V)=\sum_{S \in S_{i}} w(|s|)[v(s)-v(s \backslash i)], i=1,2, \ldots, n . \\
& w(|s|)=\frac{(n-|s|) !(|s|-1) !}{n !} .
\end{aligned}
$$

Shapley Value is a weighted average in consider of the contributions given by the members in the strategic alliance. The model takes into account the contributions of each member to the total outcome of the strategic alliance, and reflects the importance of each member to the alliance's benefits.

\section{The Revised Shapley Value Method[2,3]}

Shapley value method assumes that each member faces the exactly same influential factors, which is impossible in practice. The influential factors include the risks each member faces, the capital invested in the alliance, the extra contribution made to the alliance during cooperation and the comprehensive strength differences of each member respectively. These factors should be considered in the Shapley model to better reflect the real situation, thus a more reasonable profit distribution will be made.

The Risk Revision Factor. First of all, different companies favor different risks, even in cooperation each member is confronted with risks of different kinds. The international logistics alliance should embody the principle of "sharing both the benefits and risks". The company which undertakes bigger risks should get more benefits. However in Shapley model, it assumes each member faces risks of $1 / \mathrm{n}$, which means an average level. Now a risk revision factor $\Delta \mathrm{r}_{i}=r_{i}-1 / \mathrm{n}$ is introduced to the model. $r_{i}$ stands for the risks faced by company $\mathrm{i}$, and could be calculated by using comprehensive fuzzy evaluation. The value difference $\Delta r_{i}$ is the revision to different risks faced. When $r_{i} \geq 0$, it means company i confronts a higher risk level than average, which means it should get more profit as $\Delta \mathrm{r}_{i} \cdot \varphi_{\mathrm{i}}(\mathrm{v})$; When $r_{i} \leq 0$, it means that the company is with lower risk, and its benefit should be reduced by $\Delta \mathrm{r}_{i} \cdot \varphi_{\mathrm{i}}(\mathrm{v})$. Thus, by introducing a risk factor into the model, company i should get benefit as Eq. 4.

$$
\varphi_{i}^{\prime}(\mathrm{v})=\varphi_{\mathrm{i}}(\mathrm{v})+\Delta \mathrm{r}_{\mathrm{i}} \cdot \varphi_{\mathrm{i}}(\mathrm{v}) .
$$

The Investment Proportion. Regardless of a company's scale or competitiveness, the capital invested in the alliance by each member should be taken into consideration. Certain weight should be attached to show the inflow capital, equipment, staff, brand value and the market value invested by each company. The investment vector can be written as $I=\left\{I_{1}, I_{2}, . . I_{n}\right\}$; the profit distribution after revision is Eq. 5.

$$
\varphi_{i}^{\prime}(\mathrm{v})=\mathrm{I}_{\mathrm{i}} /\left(\sum_{\mathrm{i}=1}^{\mathrm{n}} \mathrm{I}_{\mathrm{i}}\right) \cdot V(\mathrm{~N}), \mathrm{i}=(1,2, . ., \mathrm{n}) .
$$

The Compensation for Extra Contribution. The coefficient of compensation for extra contribution is $\theta_{i} \in[0,1]$. In the practical operation of logistics, emergencies like transportation delay and cost increase in stock control due to terrible weather, transportation equipment damage , exchange rate fluctuation in international trades constantly bring extra fees to alliance members. 
Considerations should be given to it during profit distribution. The value of the coefficient can be determined by negotiation among alliance members according to the situation. After $\theta_{i}$ is determined, the real revision amount of extra contribution can be written as $\Delta e_{i}=\theta_{i}-1 / n$. So the actual distributed profit should be Eq. 6 .

$$
\varphi_{i}^{\prime}(\mathrm{v})=\varphi_{\mathrm{i}}(\mathrm{v})+\Delta \mathrm{e}_{i} \cdot V(\mathrm{~N}) .
$$

The Revision Considering the Comprehensive Strength. In Shapley method it is assumed that the members in the strategic alliance have more or less the same strength. However, there are plenty of typical alliances consist of both strong and weak members. The comprehensive strength of a logistics company can include the scale of the company, the core competitiveness, brand, strategic management ability and so on. If a member has a strong comprehensive ability, certain additional profit should be distributed to it to maintain the stability of the alliance. AHP (Analytic Hierarchy Process) method could be used to decide the weight of the comprehensive ability. The weight vector can be expressed as $w_{i}=\left\{\mathrm{w}_{1}, \mathrm{w}_{2}, . ., \mathrm{w}_{\mathrm{n}}\right\}$. Use the weighted vector to revise the factor as $\Delta \mathrm{w}_{i}=w_{i}-1 / n$. Thus, the revised distribution amount is Eq. 7 .

$$
\varphi_{i}^{\prime}(\mathrm{v})=\varphi_{\mathrm{i}}(\mathrm{v})+\Delta \mathrm{w}_{i} \cdot V(\mathrm{~N})
$$

\section{Algorithm}

Assume a strategic alliance consists of 3 companies, $\mathrm{A}, \mathrm{B}$ and $\mathrm{C}$. If the 3 companies run separately, company A can realize a profit of 100 thousand, B can get 300 thousand while C get 150 thousand. If $\mathrm{A}$ and $\mathrm{B}$ cooperate as an alliance, the benefit will be 600 thousand; if $\mathrm{A}$ and $\mathrm{C}$ cooperate, the profit is 400 thousand, if $\mathrm{B}$ and $\mathrm{C}$, the benefit will be 750 thousand. If $\mathrm{A}, \mathrm{B}$ and $\mathrm{C}$ found a strategic alliance, they would realize a 1500-thousand profit. If the 3 companies share the profit, each will get 500 thousand. Although this income is higher than what they can get if they run the business separately, the companies are not interested in it.

The Application of Shapley Value Method. The strategic alliance of the 3 companies is $\mathrm{N}=\{1,2,3\}$; their respective benefits are $\mathrm{v}(1)=100, \mathrm{v}(2)=300, \mathrm{v}(3)=150$. The benefit earned by company A and B is $v(1 \cup 2)=600$, A and C is $v(1 \cup 3)=400$, B and C is $v(2 \cup 3)=750$, the 3 together is $v(1 \cup 2 \cup 3)=1500$. The profit of company A in different alliances is shown in Table 1 . Add the figures in the last row of the diagram and we can get the Shapley Value of company A is 375 thousand. In the same way, we can get company B and company C's profit distribution. As shown in Table 2 and Table 3. Company B can get a profit of 650 thousand while company $\mathrm{C}$ gets 475 thousand. The Shapley value method distribution shows how important each member is to the whole strategic alliance. In the distribution, $v(1 \cup 2 \cup 3)=1500$, meanwhile, the benefit summation of every 2 companies in the 3-company alliance is higher than 2-company alliance, thus this is the most stable alliance. The principle of distributing according to contribution in Shapley value gets rid of the disadvantages of dividing the profit equally, thus to interest members and bring stability to the alliance.

Table 1 the Profit Distribution to Company A

\begin{tabular}{|c|c|c|c|c|}
\hline $\mathrm{S}$ & 1 & $1 \cup 2$ & $1 \cup 3$ & $1 \cup 2 \cup 3$ \\
\hline $\mathrm{v}(\mathrm{S})$ & 100 & 600 & 400 & 1500 \\
\hline$v(s \backslash 1)$ & 0 & 300 & 150 & 750 \\
\hline$v(s)-v(s \backslash 1)$ & 100 & 300 & 250 & 750 \\
\hline$|\mathrm{S}|$ & 1 & 2 & 2 & 3 \\
\hline $\mathrm{w}|\mathrm{S}|$ & $1 / 3$ & $1 / 6$ & $1 / 6$ & $1 / 3$ \\
\hline$w(s \mid)[v(s)-v(s \backslash 1)]$ & $100 / 3$ & 50 & $250 / 6$ & 250 \\
\hline \multicolumn{5}{|c|}{ Table 2 the Profit Distribution to Company B } \\
\hline $\mathrm{S}$ & 2 & $1 \cup 2$ & $2 \cup 3$ & $1 \cup 2 \cup 3$ \\
\hline $\mathrm{v}(\mathrm{S})$ & 300 & 600 & 750 & 1500 \\
\hline
\end{tabular}




\begin{tabular}{|c|c|c|c|c|}
$v(s \backslash 2)$ & 0 & 100 & 150 & 400 \\
\hline$v(s)-v(s \backslash 2)$ & 300 & 500 & 600 & 1100 \\
\hline$|S|$ & 1 & 2 & 2 & 3 \\
\hline $\mathrm{w}|\mathrm{S}|$ & $1 / 3$ & $1 / 6$ & $1 / 6$ & $1 / 3$ \\
\hline$w(s)[v(s)-v(s \backslash 2)]$ & 100 & $250 / 3$ & 100 & $1100 / 3$ \\
\hline
\end{tabular}

Table 3 the Profit Distribution to Company C

\begin{tabular}{|c|c|c|c|c|}
\hline $\mathrm{S}$ & 3 & $1 \cup 3$ & $2 \cup 3$ & $1 \cup 2 \cup 3$ \\
\hline $\mathrm{v}(\mathrm{S})$ & 300 & 600 & 750 & 1500 \\
\hline$v(s \backslash 3)$ & 0 & 100 & 150 & 400 \\
\hline$v(s)-v(s \backslash 3)$ & 300 & 500 & 600 & 1100 \\
\hline$|\mathrm{S}|$ & 1 & 2 & 2 & 3 \\
\hline$w|S|$ & $1 / 3$ & $1 / 6$ & $1 / 6$ & $1 / 3$ \\
\hline$w(s \mid)[v(s)-v(s \backslash 3)]$ & 100 & $250 / 3$ & 100 & $1100 / 3$ \\
\hline
\end{tabular}

The Application of Revised Shapley Value Model. Firstly, introduce in the risk factor. Assume by using a comprehensive fuzzy evaluation method we get the coefficients of the risks the 3 companies in cooperation face, which are $r_{1}=0.3, r_{2}=0.3, r_{3}=0.4$; according to $\Delta r_{i}=r_{i}-1 / n$, the risk revised factor can be calculated as $\Delta \mathrm{r}_{1}=-1 / 30, \Delta \mathrm{r}_{2}=-1 / 30, \Delta \mathrm{r}_{3}=1 / 15$. Thus after introducing the risk factors into the model, each company's benefits distributed are $\phi_{1}^{\prime}(\mathrm{v})=362.5, \phi_{2}^{\prime}(\mathrm{v})=628.33$, $\phi_{3}^{\prime}(v)=506.67$. Secondly, introduce in the investment weight. Assume that the 3 companies invested 300, 450 and 350 thousand Yuan respectively on joining the alliance (including intangible value), the revised Shapley value can be calculated as $\phi_{1}^{\prime}(\mathrm{v})=409.09, \phi_{2}^{\prime}(\mathrm{v})=613.64, \phi_{3}^{\prime}(\mathrm{v})=477.28$. Thirdly, introduce in the compensation for extra contribution. Assume that the coefficients of each company for extra contribution are $\theta_{1}=0.3, \theta_{2}=0.4, \theta_{3}=0.3$ according to the negotiation, G3 $=0.3$, thus the revised values considering extra contribution are $\Delta e_{1}-1 / 30, \Delta e_{2}=1 / 15, \Delta e_{3}=-1 / 30$. The revised Shapley values are $\phi_{1}^{\prime}(\mathrm{v})=325, \quad \phi_{2}^{\prime}(\mathrm{v})=750, \quad \phi_{3}^{\prime}(\mathrm{v})=425$ respectively. Fourthly, revise according to the comprehensive strength. Assume that the weights of comprehensive strength of the 3 companies are $\mathrm{w}_{1}=0.2, \mathrm{w}_{2}=0.5, \mathrm{w}_{3}=0.3$ using AHP method, the revised value differences are $\Delta \mathrm{w}_{1}=-2 / 15$, $\Delta \mathrm{w}_{2}=1 / 6, \Delta \mathrm{w}_{3}=-1 / 30$. Thus the profit distribution taken comprehensive ability of each company into consideration should be $\phi_{1}^{\prime}(\mathrm{v})=175, \phi_{2}^{\prime}(\mathrm{v})=900, \phi_{3}^{\prime}(\mathrm{v})=425$.

\section{The Comparison of Methods}

Assume that the weight of each revised factor using AHP method is 0.4, 0.3, 0.2 and 0.1 respectively, the final profit distribution method using the revised Shapley value model is shown in Table 4. The final profit distribution method considering all the factors is that company A gets 350.23 thousand Yuan, company B gets 675.42 thousand Yuan and company C gets 473.35 thousand Yuan. The revised Shapley model gets rid of the disadvantages of average distribution, and exceeds Shapley model itself in better reflecting the real conditions. Using this distribution method, each member in the strategic alliance obtains more income than by running solely or in 2-member alliance, which contributes to the stability of the alliance.

Table 4 the Different Distribution Methods Comparison

\begin{tabular}{|c|c|c|c|c|}
\hline Distributed Profit & A & B & C & Weight \\
\hline Running Separately & 100 & 300 & 150 & \\
\hline Distribute Averagely & 500 & 500 & 500 & 1500 \\
\hline Shapley Value Method & 375 & 650 & 475 & 1500 \\
\hline With Risk Factor & 362.5 & 628.33 & 506.67 & 0.4 \\
\hline With Investment Factor & 409.09 & 613.64 & 477.28 & 0.3 \\
\hline Extra Contribution & 325 & 750 & 425 & 0.2 \\
\hline Strength Factor & 175 & 900 & 425 & 0.1 \\
\hline Final Distribution & 350.227 & 675.424 & 473.352 & 1500 \\
\hline
\end{tabular}




\section{Conclusion}

In order to solve the profit distribution problem in strategic alliances, Shapley model considers how much each member contributes to the total income of the alliance; provides a better distribution method than the average one. However, the conditions assumed in Shapley model that each member company confronts the same environment is inflexible in real conditions. The revised Shapley value introduces factors such as risk, investment, extra contribution and companies' comprehensive strength into the model, which makes Shapley model more flexible and more realistic. Through the examples, a comparatively reasonable distribution method can be obtained.

\section{References}

[1] Chen Zhi, Duan Guijun. Research on the Profit Distribution of Liner Shipping Alliance Based on Shapley Value [J]. Journal of Transportation Engineering and Information, 2005, No.4 Vol.3:55-64

[2] Li Ouyang. Research on the Interests Distribution of the Third-party Logistics Enterprises Strategic Alliance [D]. Central South University,2011

[3] Jiu Xiaotao, Xu Qi. Risk-considered Shapley Profit Distribution Model of Apparel Supply Chain[J].Logistics Technology, 2009,No.12 Vol.28:179-181

[4] M. Frisk, M. Göthe-Lundgren, K. Jörnsten, M. Rönnqvist. Cost allocation in collaborative forest transportation[J]. European Journal of Operational Research, 2010, 205(2): 448-458

[5] Tan X, Lie TT. Application of the Shapley value on transmission cost allocation in the competitive power market environment[J]. IEE Proceedings Generation, Transmission and Distribution, 2002, 149(1):15-20 